\title{
Common Stochastic Trends, Common Cycles, and Asymmetry in Economic Fluctuations
}

\author{
Chang-Jin Kim* \\ Korea University \\ Jeremy Piger \\ Board of Governors of the Federal Reserve System
}

October 1999

Last Revised: July 24, 2000

\begin{abstract}
This paper investigates the nature of business cycle asymmetry using a dynamic factor model of output, investment, and consumption. We first identify a common stochastic trend and a common transitory component by imbedding the permanent income hypothesis within a simple growth model. We then investigate two types of asymmetry commonly identified in U.S. business cycle dynamics: 1. Infrequent negative permanent shocks, modeled as shifts in the growth rate of the common stochastic trend and 2. Infrequent negative transitory shocks, modeled as "plucking" deviations from the common stochastic trend. Tests of marginal significance suggest both types of asymmetry were present in post-war recessions, although the shifts in trend are less severe than the received literature suggests.
\end{abstract}

Key words: Asymmetry, Business Cycles, Common Shocks, Markov-Switching, Productivity Slowdown J.E.L classification: C32, E32

\footnotetext{
${ }^{*}$ Kim: Dept. of Economics, Korea University, Anam-Dong, Seongbuk-ku, Seoul, 136-701, Korea, (cjkim@ kuccnx.korea.ac.kr); Piger (Corresponding Author): Mail Stop 23, Washington, D.C. 20551, (Jeremy.M.Piger@frb.gov). Kim acknowledges support from the National Science Foundation under grant SES9818789 and from the Department of Economics at the University of Washington. Piger acknowledges support from the Grover and Creta Ensley Fellowship in Economic Policy. The authors are grateful to James Morley, Charles Nelson, Jessica Rutledge, Dick Startz, Eric Zivot and seminar participants at the University of Washington, the Board of Governors of the Federal Reserve, and the Federal Reserve Banks of Dallas, St. Louis and Kansas City for useful comments. Responsibility for errors are entirely the authors'. The views expressed herein are those of the authors and do not necessarily represent those of the Board of Governors of the Federal Reserve System or its staff.
} 
The question of whether the dynamics of recessions are different from those of expansions has a long history. Early students of the business cycle, including Mitchell (1927), Keynes (1936), and Burns and Mitchell (1946) noted that declines in economic activity take hold quicker, are steeper, and last for a shorter amount of time than expansions. To these observers, recessions appeared to come from a different regime than booms. Recent interest in this type of asymmetry was sparked by Salih Neftci (1984), who presented evidence that increases in the unemployment rate are sharper and shorter than declines.

Since that time, two parametric time-series models of U.S. output were proposed that are capable of capturing steep, short recessions. However, they are fundamentally different in their implications for the effects of recessions on the long run level of output. In other words, the hypothesized persistence of shocks that lead to recessions is very different in the two models. The first model, due to Hamilton (1989), divides the business cycle into two phases, negative trend growth and positive trend growth, with the economy switching back and forth according to a latent state variable. This two phase business cycle implies that following the trough of a recession, output switches back to the expansion growth phase, never regaining the ground lost during the downturn. Recessions will therefore have permanent effects on the level of output. The second model, having its roots in work by Friedman $(1964,1993)$ and recently formalized in an econometric model by Kim and Nelson (1999b), suggests that recessions are periods where output is hit by large negative transitory shocks, labeled "plucks" by Friedman. Following the trough, output enters a high growth recovery phase, returning to the trend. This "bounce-back effect" or "peak-reversion" is the critical phase of Friedman's model. Output then begins a normal, slower growth, expansion phase. Thus, Friedman's view is that recessions are entirely transitory deviations from trend, not movements in the trend itself. 
Both forms of asymmetry have received substantial attention in the empirical literature, with conflicting conclusions. Using classical likelihood based tests, Hansen (1992) and Garcia (1998) both fail to reject a linear autoregressive model in favor of Hamilton's model for U.S. GNP. Kim and Nelson (1999c) reach a similar conclusion using Bayesian methods. On the other hand, both Chib (1995) and Koop and Potter (1999) find evidence in favor of Hamilton's model using Bayesian techniques. Support for the peak-reversion implication of Friedman's model is given by Wynne and Balke (1992, 1996), Sichel (1993, 1994), and Beaudry and Koop (1993). However, Elwood (1998) argues that the evidence in favor of peak-reversion has been overstated. Specifically, Elwood presents evidence that negative shocks are not significantly less persistent than positive ones for U.S. GNP. A shortcoming of this empirical literature is that most authors have analyzed the two forms of asymmetry separately from one another. That is, little attention is paid to evaluating the marginal significance of the two forms of asymmetry. ${ }^{1}$ An additional shortcoming is the literature's domination by univariate analysis. As pointed out by Kim and Nelson (1999a), tests based on univariate models have low power in detecting a specific form of asymmetry in the business cycle as the data may be obscured by idiosyncratic variation.

In this paper, we estimate a dynamic two-factor model of real private GNP, fixed investment, and consumption of non-durables and services that incorporates the common stochastic trend suggested by neoclassical growth theory and a common transitory component. Building on work by Cochrane (1994) and Fama (1992) we define consumption as the common stochastic trend. As we discuss below, this assumption can help to eliminate bias that may arise

\footnotetext{
${ }^{1}$ An exception is Kim and Murray (1999), who estimate an experimental coincident index of economic activity which incorporates both types of asymmetry discussed above. However, their investigation employs economic indicators that are not cointegrated. Also, they do not investigate the implications of their model for the dynamics of real GNP.
} 
when using Hamilton's model to capture shifts in trend growth rate. We model the Hamilton and Friedman types of asymmetry through regime switching in the permanent and transitory components respectively. This method allows tests of the marginal significance of one type of asymmetry while the other is allowed to be present. As a byproduct of the estimation we consider the possibility of a one-time structural break in the growth rate of the common stochastic trend (a productivity slowdown). We search for the date of this break using a multivariate version of a technique suggested by Kim and Nelson (1999c).

Section 1 of the paper presents a review of the Hamilton and Friedman types of asymmetry in business cycle dynamics. Section 2 discusses the theory supporting a common stochastic trend and a common cyclical component in output, investment and consumption, presents the formal empirical model, and discusses the technique used to search for a one-time structural break. Section 3 presents estimation results and statistical tests of the importance of the two types of asymmetry. Such tests suggest that both types of asymmetry have played a significant role in post-war recessions, although the nature of shifts in the growth rate of trend is different than the received literature suggests. In particular, we find evidence of reduced, but still positive, growth rates in trend during recessions, not the negative trend growth suggested by Hamilton (1989). We present some simulation evidence that this discrepancy may be caused by a potential bias in applying Hamilton's model to data which undergoes “plucking” type recessions. The investigation of a one-time structural break in the average growth rate of trend is suggestive of a productivity slowdown, the estimated date of which is centered around 1974. Section 4 summarizes and concludes. 


\section{A Review of the Hamilton and Friedman Models}

\subsection{Hamilton’s (1989) Model}

In an influential 1989 Econometrica paper, James Hamilton proposed a model in which the growth rate of the trend function of U.S. GNP switches between two different states according to a first order Markov process. Hamilton's results suggest the two states correspond to business cycle dynamics, the first being normal growth and the second recession. Figure 1 contains a stylized graph of a business cycle characterized by Hamilton type asymmetry. Note that following the recession output does not rebound back to its level had the recession not occurred. Instead, because recessions are movements in the trend of the series, output is permanently lower. Specifically, Hamilton's results suggest that a typical economic recession is characterized by a $3 \%$ permanent drop in the level of GNP. Thus, while the Hamilton model is capable of explaining a business cycle in which recessions are quick, steep drops in economic activity, it also has a dire implication for the welfare effects of recessions.

Evaluation of Hamilton's model is complicated by the fact that standard distribution theory for hypothesis testing does not apply to Markov-switching models. Testing the Markovswitching model vs. linear alternatives is troubled by the familiar Davies' (1977) problem, in which a nuisance parameter is not identified under the null hypothesis. Hamilton's original paper offers suggestive evidence that the two state Markov-switching model outperforms linear models in terms of forecasts, but no statistical tests. Hansen (1992) and Garcia (1998) use classical likelihood based test procedures designed to deal with the Davies' problem and find that linear autoregressive models cannot be rejected for real GNP. Kim and Nelson (1999a) confirm this result using Bayesian techniques. Also using Bayesian techniques, Chib (1995) and Koop and 
Potter (1999) find evidence that the Markov-switching model outperforms linear models. Thus, the empirical evidence regarding Hamilton's model is mixed and incomplete.

In an example of estimation preceding theory, Hamilton's model has been followed by a growing volume of theoretical work in which the economy undergoes endogenous switching between "good" and "bad" states. Specifically, Howitt and McAfee (1992) employ a model of switching consumer confidence which leads to multiple equilibria with statistical properties well characterized by Markov-switching. In Cooper (1994), agents choose between multiple equilibria and then remain in the chosen equilibrium until a large shock induces a switch. Acemoglu and Scott (1993) and Startz (1998) also employ models in which shocks generate endogenous switching between growth states. However, negative growth states, such as those found by Hamilton (1989) during recessions, are not generated by these models in general. For example, in Startz (1998) the economy switches between two positive growth states.

\subsection{Friedman's (1964, 1993) “Plucking” Model}

Friedman $(1964,1993)$, argued for a type of business cycle asymmetry that, while yielding steep recessions, has very different implications for the long run effects of recessions than Hamilton's model. ${ }^{2}$ Specifically, in Friedman's "plucking" model, recessions are caused by large negative transitory shocks which yield steep recessions. Following these shocks output "bounces back" or "peak reverts" to trend. This is commonly referred to as the high growth recovery phase. Finally, output begins a normal, slower growth, expansion. ${ }^{3}$ Figure 2 contains a stylized graph of a business cycle characterized by "plucking".

\footnotetext{
${ }^{2}$ The behavior described in this paragraph is also consistent with De Long and Summers' (1988) "output gaps".

${ }^{3}$ Friedman's "plucking" model has another strong implication - that deviations from trend are only negative, meaning increases in output are permanent. In this paper we do not attempt to model this feature. Instead we focus on the peak reversion of recessions, or the tendency of output to "bounce back".
} 
The literature contains many statistical tests of various implications of Friedman's model. Here we focus on the literature surrounding the peak-reverting nature of recessions. Wynne and Balke $(1992,1996)$ find that the deeper the recession the stronger the ensuing recovery while Sichel (1994) finds evidence of a high growth recovery phase following recessions, both implications of peak reversion. Another implication of peak reversion is that negative shocks are less persistent than positive shocks. ${ }^{4}$ Beaudry and Koop (1993) showed that a variable measuring the depth of real GNP below its historic high was useful for predicting changes in output. They use this variable to investigate impulse response functions for negative vs. positive shocks, and show that negative shocks are much less persistent. Elwood (1998) took issue with Beaudry and Koop's techniques, arguing that by considering only shocks which reduce the level of GNP they ignore a large number of negative shocks that fail to reduce the level of the series. Elwood uses an unobserved components model capable of identifying all negative and positive shocks and finds that negative shocks are not statistically significantly less persistent than positive shocks. This controversy is suggestive of two kinds of negative shocks to the economy, large, asymmetric, recession causing shocks and smaller shocks which come from a symmetric process. Beaudry and Koop's analysis proxies for the large negative shocks by considering only shocks which actually reduce the level of GNP. On the other hand, Elwood's analysis smears the effects of large and small negative shocks together by assuming all negative shocks have the same variance. In this paper we take the approach of Kim and Nelson (1999b) and allow for both continuous, symmetric transitory shocks and infrequent, asymmetric transitory shocks, which we model as coming from a Markov-switching process.

\footnotetext{
${ }^{4}$ If recessions are entirely transitory, as Friedman's model suggests, while expansions, being driven in part by a stochastic trend, have a permanent component, negative shocks will have less persistence than positive shocks.
} 
The type of recessions Friedman's model describes are consistent with a wide variety of economic models. In demand driven models, output might be driven into recession by a large infrequent demand shock. Following the recession, output grows faster than when at trend because resources are underutilized. Walrasian models can also generate a high growth recovery phase if recessions are partially absorbed by running down the capital stock. Then, just as in the Solow growth model, the economy will experience faster growth until the capital stock is restored to its new steady state value.

\subsection{Do Both Types of Asymmetry Matter?}

Empirical work has focused on either the Hamilton or Friedman type of asymmetry separately, a consequence of the prevalence of univariate techniques. However, since the two types of asymmetry both capture the steep, sharp nature of recessions, both might provide improvement over linear models if considered separately. For example, in Section 3 we present simulation evidence that Hamilton's model will fit data generated with Friedman type asymmetry with a positive and negative growth state in the stochastic trend, even though all recessionary shocks are transitory. To evaluate whether both types of asymmetry are important one must employ a model that separates the two types of asymmetry from one another. In the following section we present a model capable of achieving this separation and testing the marginal significance of each type of asymmetry when the other is allowed to be present.

\section{Model Motivation and Specification}

\subsection{Common Permanent and Transitory Components - Theory}

The concept of trend vs. cycle plays an important role in defining the Hamilton and Friedman types of asymmetry. One advantage of our multivariate model of output, investment 
and consumption is its natural interpretation of trend provided by neoclassical growth theory. To see this, consider a basic one-sector model of capital accumulation based on that in King, Plosser, and Rebelo (1988). Output is produced by two factors, capital and labor, and is subject to exogenous growth in labor augmenting technology, $A_{t}$ :

$Y_{t}=F\left(K_{t}, A_{t} L_{t}\right)$

Each representative agent in the economy has identical preferences over the consumption of goods, $C_{t}$ and leisure, $R_{t}$ given by:

$U=\sum_{t=0}^{\infty} \beta^{t} u\left(C_{t}, R_{t}\right)$

where utility is increasing in both consumption and leisure. Finally, the capital accumulation process is:

$$
K_{t+1}=(1-d) K_{t}+I_{t}
$$

where $d$ is the rate of depreciation on capital and $I_{t}$ is investment. The economy is also subject to constraints on the amount of time a worker has to allocate between work and leisure and the amount of consumption and investment possible for a given level of output. If a steady state exists in this model it will be one in which the logarithms of output, investment, and consumption grow at a rate determined by labor augmenting technological progress. In the case where there are permanent technology shocks, as is the case if the logarithm of $A_{t}$ follows a random walk, these three quantities share a common stochastic trend. ${ }^{5}$ Each series is then individually integrated but can be combined with either of the other two in a linear combination

\footnotetext{
${ }^{5}$ A steady state under random walk productivity growth, called a stochastic steady state, will obtain under restrictions on preferences and production technology, (Cobb-Douglas production is not required). The interested reader is referred to King, Plosser and Rebelo (1988) and King and Rebelo (1987) for details.
} 
that is stationary. In the terminology of Engle and Granger (1987), the logarithms of output, fixed investment and consumption are cointegrated with cointegrating vectors $(1,-1,0)$ ' and (1, $0,-1)^{\prime}$

In this paper we employ consumption as a proxy for the common stochastic trend in the system. The recent literature, for example Fama (1992) and Cochrane (1994), suggests that while consumption does seem to contain a statistically significant transitory component, it is so small as to be economically insignificant. Based on this result, Fama (1992) chooses to define consumption as the common stochastic trend in output, investment, and consumption. Cochrane (1994) argues that consumption is an effective measure of the trend in output by presenting evidence that shocks to GNP holding consumption constant are almost entirely transitory, a result consistent with simple versions of the permanent income hypothesis. Defining consumption as the trend serves a useful purpose in this paper. As we argued above, because both the Hamilton and Friedman models are capable of capturing the steep nature of recessions, either may fit the data well even if the data exhibits only one type of asymmetry. Simulation evidence in Section 3 support this conclusion. Thus, in order to separate the two forms of asymmetry, we would like to define the Hamilton type of asymmetry on a series that proxies for only the trend and does not undergo the transitory Friedman type asymmetry. Consumption is a useful proxy for this trend.

In the neoclassical growth model, movements in the stochastic trend account for all of the movement in output, investment, and consumption in the long-run. However, at business cycle horizons transitory deviations from this stochastic trend are likely to be important. For example, many real business cycle models, such as Kydland and Prescott (1982), extend the model 
presented above in ways that allow technology shocks to induce transitory dynamics as the economy moves towards the new steady state. Transitory deviations from a long run stochastic trend might also come from more traditional demand-side nominal shocks. Regardless of whether transitory shocks stem from Walrasian or Keynesian sources however, it is likely that some portion of the shocks will come from sources that are common to output, investment, and consumption. For example, if shocks to the money supply have real, albeit transitory, effects, one would expect that these effects would be pervasive across macroeconomic time series. Likewise, if general productivity shocks induce transitory dynamics, these dynamics should be felt economy-wide. Thus, in addition to the common stochastic trend suggested by neoclassical growth theory, we would also expect common sources of transitory dynamics at business cycle horizons.

\subsection{A Dynamic Two-Factor Regime Switching Model}

The above discussion is suggestive of a general empirical model in which the logarithms

of output, $y_{t}$, and investment, $i_{t}$, are influenced by shocks to a common stochastic trend, defined as the logarithm of consumption, $c_{t}$, a common transitory component, and idiosyncratic transitory shocks. The common stochastic trend and common transitory component are captured by two dynamic factors, labeled $x_{t}$ and $z_{t}$ :

$$
\begin{aligned}
& y_{t}=a_{y}+\gamma_{y} x_{t}+\lambda_{y} z_{t}+e_{y t} \\
& i_{t}=a_{i}+\gamma_{i} x_{t}+\lambda_{i} z_{t}+e_{i t} \\
& c_{t}=a_{c}+\gamma_{c} x_{t}
\end{aligned}
$$

The $e_{j t}, j=y, i$ are stationary residuals that capture idiosyncratic transitory variation in $y_{t}$ and

$i_{t} \cdot \gamma_{j}$ and $\lambda_{j}$ are factor loadings on the common stochastic trend and the common transitory component respectively. For identification, $\gamma_{y}$ and $\lambda_{y}$ are normalized to one. 
We are now ready to discuss how the two types of asymmetry are incorporated in the model. We begin with the Hamilton type asymmetry, which we incorporate as in Hamilton (1989). Recall, the Hamilton type asymmetry involves shifts in the growth rate of the trend function between two different states. Thus, we allow the common stochastic trend, $x_{t}$, to follow a random walk with a switching drift term:

$x_{t}=\mu_{1} S_{t}+\mu_{0}^{*}+x_{t-1}+v_{t}$

where $v_{t} \sim N\left(0, \sigma_{v}^{2}\right)$, and $S_{t}=\{0,1\}$ indicates the state of the economy. We assume that $S_{t}$ is driven by a first order Markov process with transition probabilities given by:

$$
\begin{aligned}
& P\left(S_{t}=1 \mid S_{t-1}=1\right)=p_{11} \\
& P\left(S_{t}=0 \mid S_{t-1}=0\right)=p_{00}
\end{aligned}
$$

To incorporate the Friedman type asymmetry we allow the idiosyncratic transitory component of output and investment to undergo regime switching as in Kim and Nelson(1999b). Formally:

$\psi_{j}(L) e_{j t}=\varepsilon_{j t}+\tau_{j} S_{t}, j=y, i$

where $\varepsilon_{j t} \sim N\left(0, \sigma_{\varepsilon j}^{2}\right), \psi_{j}(L)$ has all roots outside the unit circle, and $\tau_{j}<0$ is a term which "plucks" output and investment down when $S_{t}=1$. When the economy returns to normal times the economy reverts back to the stochastic trend. The farther the economy is plucked down, the faster the growth of the economy as it "bounces back" to trend. ${ }^{6}$

To complete the model we must specify the dynamics of the common transitory component $z_{t}$ :

\footnotetext{
${ }^{6}$ The "plucking" parameter is incorporated in the idiosyncratic transitory component of output and investment to allow for the possibility that the magnitude of the pluck might be different across economic series. However, in interpreting the model the plucks are better characterized as common shocks because they are driven by the same state variable. In other words, when output is plucked down, so is investment.
} 
$\phi(L) z_{t}=\omega_{t}$

where $\omega_{t} \sim N\left(0, \sigma_{\omega}^{2}\right)$, and $\phi(L)$ is a lag polynomial with roots that lie outside the unit circle.

For identification purposes we assume that $v_{t}, \omega_{t}, \varepsilon_{y t}$, and $\varepsilon_{i t}$ are uncorrelated at all leads and lags.

The model presented above is closely related to a recent literature discussing building models which simultaneously capture comovement and asymmetry in business cycle indicator variables. Diebold and Rudebusch (1996) discuss this idea in detail, while Kim and Yoo (1995), Chauvet (1998) and Kim and Murray (1999) all estimate such models. However, this literature is exclusively concerned with the development of a new coincident index of economic activity and not with the dynamics of real GNP. In addition, these papers consider economic variables that are not cointegrated. Finally, with the exception of Kim and Murray (1999), only the Hamilton type regime switching is used to capture asymmetry. Here, by applying a cointegrated system with a precise definition of trend we hope to gain a clearer look at the nature of both the Hamilton and Friedman types of asymmetry in the dynamics of U.S. GNP. ${ }^{7}$

Notice that the two types of regime switching are driven by the same state variable, $S_{t}$. In essence, this assumption forces all recessions to have the same relative importance of permanent vs. transitory Markov-switching shocks and can be motivated as an extension of Hamilton (1989) and Kim and Nelson (1999b). In these papers, the author's also force all

\footnotetext{
${ }^{7}$ Our model is also similar to the "common trends" representation suggested by King, Plosser, Stock and Watson (1991). There, the effects of the common and idiosyncratic transitory components above are combined into an $\mathrm{I}(0)$ disturbance which may be correlated across indicators. Their empirical analysis employs a VECM framework to investigate the relative importance of the common stochastic trend in real GNP, fixed investment, and consumption. While a VECM lends itself easily to impulse analysis, incorporation of asymmetry is difficult. Identification of asymmetry in a dynamic factor model is natural, motivating our choice of empirical model.
} 
recessions to have the same relative importance, in Hamilton's paper recessions are entirely permanent while in Kim and Nelson's they are entirely transitory. Here we extend these results to allow recessions to have both a permanent and transitory component. The assumption is important in that it allows us to test the null hypothesis that one type of asymmetry is marginally statistically insignificant when the other is present. If the two types of asymmetry were driven by separate state variables, testing this null hypothesis would be complicated by the familiar Davies' problem, or the fact that one set of Markov-switching parameters would be unidentified under the null hypothesis.

\subsection{A One Time Permanent Structural Break in Average Growth Rate}

There is a large literature suggesting that the growth rate of productivity has slowed at some point in the postwar sample, with the predominant view being that this slowdown roughly coincides with the first OPEC oil shock. For example, Perron (1989) identifies 1973 as the date of a break in the trend growth of U.S. quarterly real GNP. ${ }^{8}$ In a recent paper, Bai, Lumsdaine and Stock (1998) find evidence in favor of a productivity slowdown beginning somewhere between 1966 and 1971. Their work is particularly relevant here because they employ a multivariate model of quarterly real GNP, fixed investment, and consumption to test for and date a break in the growth rate of the common stochastic trend. Here, we will also search for a break in the growth rate of the common stochastic trend, $\mu_{0}^{*} \cdot{ }^{9}$ However, we do so in a model which allows

\footnotetext{
${ }^{8}$ Preliminary estimation of our model suggested that if a productivity slowdown is not incorporated the autoregressive dynamics of $e_{y t}, e_{i t}$, and $z_{t}$ are very persistent. This is consistent with Perron's (1989) finding that unit root tests are biased towards non-rejection if a break in mean growth is not accounted for.

${ }^{9}$ Several recent papers, including Kim and Nelson (1999c) and McConnell and Quiros (2000) have documented a reduction in the variance of U.S. GDP starting in 1984. Preliminary estimation, available from the authors upon request, suggested allowing for such a break did not change the results regarding the nature of business cycle asymmetry substantively.
} 
for asymmetries in the business cycle.

We endogenously estimate the date of the structural break using a technique based on Kim and Nelson (1999c). This method consists of defining a separate state variable, $D_{t}$, which also undergoes regime switching according to a first order Markov process independent of that for $S_{t}$. However, we restrict the switching to occur only from $D_{t}=0$ to $D_{t}=1$ and not in the opposite direction. This is accomplished by a restriction on the transition probabilities of the Markov process:

$$
\begin{aligned}
& P\left(D_{t}=1 \mid D_{t-1}=1\right)=1 \\
& P\left(D_{t}=0 \mid D_{t-1}=0\right)=q_{00}
\end{aligned}
$$

To investigate a break in the long run growth rate of the trend we define $\mu_{0}^{*}$ as follows:

$$
\mu_{0}^{*}=\mu_{0}\left(1-D_{t}\right)+\mu_{0}^{k} D_{t}
$$

\section{Estimation Results}

\subsection{A Look at the Data}

The data are quarterly observations on 100 times the logarithm of U.S. private GNP, or GNP less government expenditures, (GNPQ-GGEQ), U.S. gross private domestic business fixed investment, (GIF), and U.S. real consumption on non-durables and services, (GCNQ+GCSQ). All data was obtained from the DRI Basics Economic database and span from the first quarter of 1952 to the third quarter of 1998. DRI mnemonics appear in parentheses in the preceding.

The model presented in Section 2 imposes a common stochastic trend in the logarithms of output, investment and consumption. Thus, we are interested in the empirical evidence regarding the integration and cointegration properties of the data. First of all, using standard univariate unit root tests developed by Dickey and Fuller (1979), we fail to reject the null hypothesis that the 
logarithm of GNP, fixed investment, and consumption are integrated. ${ }^{10,11}$ Table 1 contains results of Johansen $(1991,1995)$ cointegration tests performed with 6 lags in levels. The tests indicate that the null hypothesis of no cointegrating vectors is rejected at the $1 \%$ level, while the null hypothesis of at most 1 cointegrating vector is rejected at the 5\% level. The null hypothesis of at most 2 cointegrating vectors is not rejected, suggesting there are 2 cointegrating relationships and therefore a single common stochastic trend in the system. This is consistent with the results of other investigations of the cointegration properties of output, investment, and consumption, such as King, Plosser, Stock and Watson (1991) and Bai, Lumsdaine, and Stock (1998). ${ }^{12}$

The cointegrating relationship between output, investment and consumption, along with the assumption that consumption is the trend, can help us gain further intuition into the types of asymmetry we are investigating. In particular, we can plot graphs of the trend and deviations from trend for our model, the components we use to investigate the two types of asymmetry. Figure 3 plots non-durables and services consumption, which up to a scaling factor is the trend in our system. To investigate asymmetry in the trend, the model in Section 2 allows for Markovswitching in the trend growth rate of this consumption series. Deviations from trend can be obtained by simply estimating the following cointegrating equations:

$y_{t}=\pi_{y}+b_{y} c_{t}+$ (equilibrium error) ${ }_{y}$

\footnotetext{
${ }^{10}$ The details and results of the ADF tests, which are by now familiar, are omitted. The results of these tests are available from the authors.

${ }^{11}$ Given that our model assumes structural change in the data, it might seem reasonable to consider unit root tests that are robust to a specific number of structural breaks such as those suggested by Perron (1994). However, results presented by Nelson, Piger, and Zivot (1999) suggest that such tests do not provide substantial increases in power over the ADF test when the data generating process exhibits Markov regime switching of the types considered here. ${ }^{12}$ Evans and Lewis (1993) show that cointegration tests can be biased in favor of the null hypothesis if a series in the cointegrating equation undergoes Markov regime switching. Since we reject the null hypothesis this does not seem to be a significant problem in this case.
} 
$i_{t}=\pi_{i}+b_{i} c_{t}+(\text { equilibrium error })_{i}$

where the equilibrium errors are, referring back to the model in Section 2, the counterparts of $\lambda_{y} z_{t}+e_{y t}$ for output and $\lambda_{i} z_{t}+e_{i t}$ for investment. Estimating (11) and (12) by OLS and forming these equilibrium errors gives us Figure 4. The model in Section 2 divides these equilibrium errors into shared, $z_{t}$, and idiosyncratic components, $e_{y t}$ and $e_{i t}$. We search for the transitory type of asymmetry in the equilibrium errors by allowing for large, infrequent, shocks, $\tau_{y}$ and $\tau_{i}$, driven by a latent Markov-switching variable.

\subsection{Estimation Results and Hypothesis Tests}

We estimate three versions of the model given above. Model 1 is our benchmark model with no further restrictions. Model 2 is a version that does not allow for the "plucking" type asymmetry, that is $\tau_{y}=\tau_{i}=0$. Model 3 does not allow for switches in the growth rate of the stochastic trend, that is $\mu_{1}=0$. All models are estimated via Kim's (1993a, 1993b, 1994) approximate maximum likelihood algorithm. Table 2 contains the estimated parameters and standard errors for Models 1-3. ${ }^{13}$ Our discussion will focus on model 1, the benchmark model. The other models will be of primary interest in performing hypothesis tests regarding the presence of asymmetry.

In the preceding discussion, asymmetry was defined as differences in the dynamics of a macroeconomic time series during recessions vs. expansions. In our model, the dynamics change when the state variable $S_{t}=1$. Thus, we are interested in whether the estimated filtered and smoothed probabilities that $S_{t}=1, P\left(S_{t}=1\right)$, coincides with the timing of recessions for the U.S. economy. Figures 5 and 6 show these probabilities along with the NBER recession dating.

\footnotetext{
${ }^{13}$ After various diagnostic checks, we settled on an $\mathrm{AR}(2)$ representation for all transitory dynamics.
} 
During every recession $P\left(S_{t}=1\right)$ spikes up, but is essentially zero during expansions. Thus, our model is identifying recessions as periods where output, investment, and consumption undergo changes in dynamics.

Next, we move to the topic of main interest in this paper, the marginal significance of the Hamilton and Friedman types of asymmetries. We begin with the Hamilton type of asymmetry, shifts in the common stochastic trend. The estimation results suggest that the common stochastic trend is well characterized by regime switching in its growth rate. The parameter $\mu_{1}$ is large in absolute value suggesting two distinct growth states in the common stochastic trend. By comparing Models 1 and 3 we are able to perform a likelihood ratio test of the null hypothesis that $\mu_{1}=0$, given that the Friedman type asymmetry exists. This null hypothesis is rejected at any reasonable significance level with a p-value of .004 .

While the Hamilton type asymmetry does seem to play a significant role in the data, the parameter estimates for $\mu_{0}, \mu_{0}^{k}$ and $\mu_{1}$ are suggestive of a different type of switching than that found by Hamilton (1989). In Hamilton's original paper, as well as in much subsequent work, the growth rate of the stochastic trend of U.S. GNP is positive during booms and negative during recessions. With the definition of the trend in GNP employed here, that being consumption, the growth rate of the stochastic trend simply slows during recessions. For example, the growth rate during booms when $D_{t}=0$ is 1.12 while it is 0.87 when $D_{t}=1$. The growth rates during recessions are $1.12-.68=0.44$ when $D_{t}=0$ and $0.87-0.68=0.19$ when $D_{t}=1$. In the framework of the growth model presented in Section 2 recessions are periods of slowdown in the rate of growth of total factor productivity. Thus, our model is not indicative of an economy with negative permanent shocks large enough to lower the level of the common stochastic trend. 
There are several possible explanations for the discrepancy between the results obtained by Hamilton and those presented here. First, it may be that in fact GNP does undergo large permanent drops in level during recessions but consumers respond by smoothing their consumption through these episodes. In this scenario, consumption growth might simply slow during recessions instead of turning negative. This however would imply economically significant predictive power of the output-consumption ratio for future changes in consumption, a result that is not supported by the results of Fama (1992) or Cochrane (1994). Another possibility is that the large permanent drops in GNP suggested by Hamilton's results are due to the lack of a mechanism to capture transitory types of asymmetry. If output undergoes large negative shocks that are followed by a high growth recovery phase, a Hamilton type model might provide improvement over linear models by labeling the large "plucking" shocks as a negative trend growth state and melding the high growth and normal growth phases of the recovery into a single expansion phase. Such a bias will not be present in the consumption series if movements in trend completely explain movements in consumption.

To investigate this second possibility we perform an experiment in which we generated a data series, $G_{t}$, using Kim and Nelson's (1999b) Markov-switching implementation of Friedman's "plucking” model. This data generating process is as follows:

$G_{t}=\delta_{t}+\xi_{t}$

$\delta_{t}=\alpha+\delta_{t-1}+\eta_{t}$

$\gamma(L) \xi_{t}=\tau S_{t}^{*}+\varepsilon_{t}$

where $S_{t}^{*}$ follows a first order Markov-switching process with transition probabilities $p_{11}^{*}$ and $p_{00}^{*}, \eta_{t}$ and $\varepsilon_{t}$ are both i.i.d normally distributed random variables, and $\gamma(L)$ has all roots outside the unit circle. We calibrated the data generating process using estimates from Kim and 
Nelson (1999b) for the log of U.S. real GDP multiplied by 100. Specifically, we set $\alpha=1.0$, $\tau=-1.5, \sigma_{\eta}^{2}=.7, \sigma_{\varepsilon}^{2}=.3, p_{11}^{*}=.71, p_{00}^{*}=.93$, and the lag order of $\gamma(L)$ equal to 2 with $\gamma_{1}=1.3$ and $\gamma_{2}=-0.46$. The key thing to notice in this model is that recessions are caused by large transitory shocks, $\tau$, not changes in trend growth rate. We then fit the generated data to Hamilton's (1989) model:

$\theta(L)\left(G_{t}-\tilde{\mu}_{t}\right)=\kappa_{t}$

where $\tilde{\mu}_{t}=\tilde{\mu}_{0}\left(1-\tilde{S}_{t}\right)+\tilde{\mu}_{1} \tilde{S}_{t}, \widetilde{S}_{t}$ follows a Markov-switching process with transition

probabilities $\tilde{p}_{11}$ and $\tilde{p}_{00}, \kappa_{t}$ is an i.i.d. normally distributed random variable, and $\theta(L)$ has all roots outside the unit circle and a lag order equal to 2 . The parameter estimates, presented in Table 3, are supportive of the hypothesis of a potential bias in the application of Hamilton's model to U.S. GNP. Note that the Hamilton model attempts to fit the three phase Friedman model with two phase switching in mean growth rate. The point estimate of $\tilde{\mu}_{0}$ is larger than $\alpha=1.0$, suggesting the Hamilton model is averaging the high growth recovery phase following an episode of "plucking" with the normal growth phase after $G_{t}$ has returned to trend. Perhaps more interesting, $\widetilde{\mu}_{1}$ is negative, suggesting the Hamilton model is labeling the plucks as a negative trend growth state. Given the mounting evidence suggesting that recessions contain a significant peak-reverting component this evidence is suggestive of a possible bias if Hamilton's model is fit to U.S. GNP, and a potential explanation for the discrepancy in the results we obtain using consumption as a measure of the trend.

Before leaving the behavior of the common stochastic trend we should discuss the estimate of the two cointegrating vectors in the system. Recall, the theoretical cointegrating vectors for $y_{t}, i_{t}, c_{t}$ are $(1,-1,0)^{\prime}$ and $(1,0,-1)^{\prime}$. From Table 2 we see that the estimated 
cointegrating vectors are $(1,-1.08,0)^{\prime}$ and $(1,0,-.93)^{\prime}$ which are very close to those suggested by theory. The fact that $\gamma_{c}$ is less than unity is consistent with the fact that the ratio of consumption of non-durables and services to private GNP drifted down approximately $10 \%$ over the sample. However, as pointed out by Bai, Lumsdaine and Stock (1998), the ratio of total consumption to GNP has drifted up over the sample. This discrepancy is due to a rise in the share of consumption allocated to durable goods.

Now we consider the other type of asymmetry discussed above, transitory deviations of output below a common stochastic trend. Such "plucking" behavior is also well supported by the parameter estimates. The null hypothesis that $\tau_{y}=\tau_{i}=0$, performed by comparing the loglikelihood from models 1 and 2, is rejected with a p-value equal to zero to 3 decimal places. Thus, there is strong evidence that, even after accounting for switching in trend growth rate, there is a "bounce-back" effect in real GNP and fixed investment. These transitory deviations are driven by large negative shocks, or plucks. However, there also appears to be a role for symmetric shocks. The variances of the symmetric shocks in the common transitory component and the idiosyncratic components are both large and statistically significant at the $1 \%$ level using Wald tests.

The parameter estimates are suggestive of a one-time structural break in the long run growth rate of the common stochastic trend. Our estimation results suggest a productivity slowdown - the estimate of $\mu_{0}^{*}$ is 1.12 when $D_{t}=0$ vs. 0.87 when $D_{t}=1$. The estimated date of the structural break is centered around 1974. This can be seen graphically in Figure 7 which presents the smoothed probabilities that $D_{t}=1$. The graphs are suggestive of a gradual structural break which began in the late 1960's. 
Our model also can comment on the relative responsiveness of fixed investment and real GNP to transitory shocks. In this sample the standard deviation of growth rates of fixed investment is 2.5 , nearly twice that of output. Given that fixed investment and GNP have almost identical responses to the common stochastic trend, this increased variability can only come from an increased responsiveness to symmetric common transitory shocks, $\lambda_{i}>\lambda_{y}=1$, relatively

larger symmetric idiosyncratic shocks, $\sigma_{\varepsilon i}^{2}>\sigma_{\varepsilon y}^{2}$, or relatively larger "plucks", $\tau_{i}>\tau_{y}$. The parameter estimates provide evidence for all three explanations. Fixed investment is 2.2 times as responsive to symmetric common transitory shocks as GNP. Also, the variance of idiosyncratic symmetric shocks are roughly twice as big for investment relative to GNP. Finally, plucks in investment are twice as large than those for GNP.

Figure 8 presents a stylized graph of the type of business cycle suggested by the parameter estimates of the model. During a recession, during which the economy is hit by a large transitory shock, the trend growth rate of output slows. Thus, when output rebounds back to trend following the recession output is lower than it would have been had the recession not occurred. However, there are no permanent decreases in output from its position before the recession began.

\section{Summary and Conclusion}

Many recent papers have presented evidence regarding two types of business cycle asymmetry, shifts in a stochastic trend having permanent effects on the level of output, and transitory "plucks" downward away from a stochastic trend. We have presented a model to investigate these two types of asymmetry which improves on the existing literature in two main ways: 1) it is a multivariate model of real GNP, fixed investment and consumption which allows us to 
separate out the two types of asymmetry under a precise definition of trend and 2) it allows for tests of the marginal statistical significance of each type of asymmetry when the other is allowed to be present. Hypothesis tests suggest that both types of asymmetry played a role in postwar recessions. However, shifts in the growth rate of the stochastic trend suggest productivity slowdowns during recessions, not the productivity reductions implied by the received literature. We explore a possible explanation for this discrepancy, that Hamilton's (1989) model is biased when applied to U.S. GNP by its failure to account for a transitory type of asymmetry, with a simple simulation. The simulation is supportive of the hypothesis. We also search for a structural break in the growth rate of the common stochastic trend. This search yields evidence of a productivity slowdown, the estimated date of which is centered at 1974. 


\section{Appendix: State Space Representation}

In this section of the appendix we present the state-space representation of the model given by equations 4-10 for the case where all transitory dynamics are AR(2).

Observation Equation:

$$
\left[\begin{array}{l}
\Delta y_{t} \\
\Delta i_{t} \\
\Delta c_{t}
\end{array}\right]=\left[\begin{array}{l}
\gamma_{y} *\left(\mu_{1} S_{t}+\mu_{0}^{*}\right) \\
\gamma_{i} *\left(\mu_{1} S_{t}+\mu_{0}^{*}\right) \\
\gamma_{c} *\left(\mu_{1} S_{t}+\mu_{0}^{*}\right)
\end{array}\right]+\left[\begin{array}{cccccc}
\lambda_{y} & -\lambda_{y} & 1 & 0 & -1 & 0 \\
\lambda_{i} & -\lambda_{i} & 0 & 1 & 0 & -1 \\
0 & 0 & 0 & 0 & 0 & 0
\end{array}\right] *\left[\begin{array}{l}
z_{t} \\
z_{t-1} \\
e_{y t} \\
e_{i t} \\
e_{y t-1} \\
e_{i t-1}
\end{array}\right]+\left[\begin{array}{l}
\gamma_{y} *\left(v_{t}\right) \\
\gamma_{i} *\left(v_{t}\right) \\
\gamma_{c} *\left(v_{t}\right)
\end{array}\right]
$$

Transition Equation:

$$
\left[\begin{array}{l}
z_{t} \\
z_{t-1} \\
e_{y t} \\
e_{i t} \\
e_{y t-1} \\
e_{i t-1}
\end{array}\right]=\left[\begin{array}{l}
0 \\
0 \\
\tau_{y} * S_{t} \\
\tau_{i} * S_{t} \\
0 \\
0
\end{array}\right]+\left[\begin{array}{cccccc}
\phi_{1} & \phi_{2} & 0 & 0 & 0 & 0 \\
1 & 0 & 0 & 0 & 0 & 0 \\
0 & 0 & \psi_{y 1} & 0 & \psi_{y 2} & 0 \\
0 & 0 & 0 & \psi_{y 1} & 0 & \psi_{y 2} \\
0 & 0 & 1 & 0 & 0 & 0 \\
0 & 0 & 0 & 1 & 0 & 0
\end{array}\right] *\left[\begin{array}{l}
z_{t-1} \\
z_{t-2} \\
e_{y t-1} \\
e_{i t-1} \\
e_{y t-2} \\
e_{i t-2}
\end{array}\right]+\left[\begin{array}{l}
\omega_{t} \\
0 \\
\varepsilon_{y t} \\
\varepsilon_{i t} \\
0 \\
0
\end{array}\right]
$$

where, $\mu_{0}^{*}$ is defined in equation 10 . The covariance matrix of the disturbance vector in the observation equation is given by:

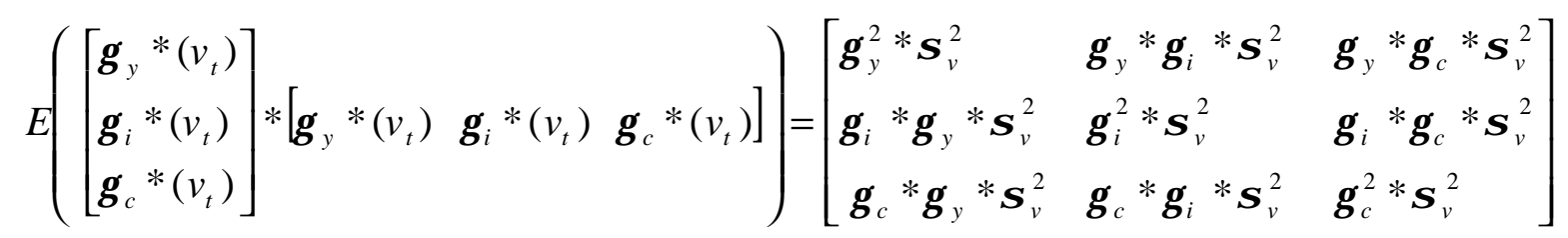

Finally, we have the covariance matrix of the disturbance vector in the transition equation:

$$
E\left[\begin{array}{l}
\omega_{t} \\
0 \\
\varepsilon_{y t} \\
\varepsilon_{i t} \\
0 \\
0
\end{array}\right] *\left[\begin{array}{llllll}
\omega_{t} & 0 & \varepsilon_{y t} & \varepsilon_{i t} & 0 & 0
\end{array}\right]=\left[\begin{array}{cccccc}
\sigma_{\omega}^{2} & 0 & 0 & 0 & 0 & 0 \\
0 & 0 & 0 & 0 & 0 & 0 \\
0 & 0 & \sigma_{\varepsilon y}^{2} & 0 & 0 & 0 \\
0 & 0 & 0 & \sigma_{\varepsilon i}^{2} & 0 & 0 \\
0 & 0 & 0 & 0 & 0 & 0 \\
0 & 0 & 0 & 0 & 0 & 0
\end{array}\right]
$$




\section{References}

Acemoglu, D. and A. Scott, 1997, Asymmetric business cycles: Theory and time-series evidence, Journal of Monetary Economics 40, 501-533.

Bai, J., R.L. Lumsdaine and J.H. Stock, 1998, Testing for and dating common breaks in multivariate time series, Review of Economic Studies 65, 395-432.

Beaudry, P. and G. Koop, 1993, Do recessions permanently change output?, Journal of Monetary Economics 31, 149-163.

Burns, A.F. and W.A. Mitchell, 1946, Measuring business cycles (NBER, New York).

Chauvet, M., 1998, An econometric characterization of business cycle dynamics with factor structure and regime switching, International Economic Review 39, 969-996.

Chib, S., 1995, Marginal likelihood from the Gibbs output, Journal of the American Statistical Association 90, 1313-1321.

Cochrane, J.H., 1994, Permanent and transitory components of GNP and stock prices, Quarterly Journal of Economics 109, 241-263.

Cooper, R., 1994, Equilibrium selection in imperfectly competitive economies with multiple Equilibria, Economic Journal 104, 1106-1122.

Davies, R.B., 1977, Hypothesis testing when a nuisance parameter is present only under the alternative, Biometrika 64, 247-254.

De Long, J.B. and L.H. Summers, 1988, How does macroeconomic policy affect output?, in W.C. Brainard and G.L. Perry, eds., Brookings papers on economic activity (The Brookings Institution, Washington, DC) 433-494. 
Dickey, D.A. and W.A. Fuller, 1979, Distribution of the estimators for autoregressive time series with a unit root, Journal of the American Statistical Association 74, 427-31.

Diebold, F.X. and G.D. Rudebusch, 1996, Measuring business cycles: A modern perspective, The Review of Economics and Statistics 78, 67-77.

Elwood, S.K., 1998, Is the persistence of shocks to output asymmetric ?, Journal of Monetary Economics 41, 411-426.

Engle, R.F. and C.W.J. Granger, 1987, Cointegration and error correction: Representation, estimation, and testing, Econometrica 55, 251-276.

Evans, M.D.D. and K.K. Lewis, 1993, Trend in excess returns in currency and bond markets, European Economic Review 37, 1005-1019.

Fama, E.F., 1992, Transitory variation in investment and output, Journal of Monetary Economics 30, 467-480.

Friedman, M., 1964, Monetary Studies of the National Bureau, the National Bureau enters its $45^{\text {th }}$ Year, $44^{\text {th }}$ Annual Report, 7-25 (NBER, New York); Reprinted in Friedman, M., 1969, The optimum quantity of money and other essays (Aldine, Chicago).

Friedman,, M. 1993, The "plucking model" of business fluctuations revisited, Economic Inquiry $31,171-177$.

Garcia, R., 1998, Asymptotic null distribution of the likelihood ratio test in Markov switching models, International Economic Review 39, 763-788.

Hamilton, J.D., 1989, A new approach to the economic analysis of nonstationary time series and the business cycle, Econometrica 57, 357-384.

Hansen, B.E., 1992, The likelihood ratio test under nonstandard conditions: testing the Markov switching model of GNP, Journal of Applied Econometrics 7, S61-S82. 
Howitt, P. and P. McAfee, 1992, Animal spirits, American Economic Review 82, 493-507.

Johansen, S., 1991, Estimation and hypothesis testing of cointegration vectors in Gaussian vector autoregressive models, Econometrica 59, 1551-1580.

Johansen, S., 1995, Likelihood-based inference in cointegrated vector autoregressive models (Oxford University Press, Oxford).

Keynes, J.M., 1936, The general theory of employment, interest, and money (Macmillan, London).

Kim, C.-J., 1993a, Unobserved-component time series models with Markov-switching heteroskedasticity: Changes in regime and the link between inflation rates and inflation uncertainty, Journal of Business and Economic Statistics 11, 341-349.

Kim, C.-J., 1993b, Sources of monetary growth uncertainty and economic activity: The time varying parameter model with heteroskedastic disturbances, Review of Economics and Statistics 75, 483-492.

Kim, C.-J., 1994, Dynamic linear models with Markov-switching, Journal of Econometrics $60,1-22$.

Kim, C.-J. and C.J. Murray, 1999, Permanent and transitory components of recessions, Discussion Paper, Department of Economics, University of Washington.

Kim, C.-J. and C.R. Nelson, 1999a, A Bayesian approach to testing for Markov-switching in univariate and dynamic factor models, International Economic Review, Forthcoming.

Kim, C.-J. and C.R. Nelson, 1999b, Friedman's plucking model of business fluctuations: Tests and estimates of permanent and transitory components, Journal of Money, Credit and Banking 31, 317-34. 
Kim, C.-J. and C.R. Nelson, 1999c, Has the U.S. economy become more stable? A Bayesian based approach based on a Markov switching model of the business cycle, Review of Economics and Statistics, Forthcoming.

Kim, M.-J. and J.-S. Yoo, 1995, New index of coincident indicators: A multivariate Markov switching factor model approach, Journal of Monetary Economics 36, 607-630.

King, R.G., C.I. Plosser and S.T. Rebelo, 1988, Production, growth and business cycles: II. new directions, Journal of Monetary Economics 21, 309-341.

King, R.G., C.I. Plosser, J.H. Stock and M.W. Watson, 1991, Stochastic trends and economic fluctuations, American Economic Review 81, 819-840.

King, R.G. and S.T. Rebelo, 1987, Stochastic steady states, Unpublished Manuscript, Department of Economics, University of Rochester.

Koop, G. and S.M. Potter, 1999, Bayes factors and nonlinearity: evidence from economic time series, Journal of Econometrics 88, 251-281.

Kydland, F.E. and E.C. Prescott, 1982, Time to build and aggregate fluctuations, Econometrica $50,1345-1370$.

McConnell, M.M. and G.P. Quiros, 2000, Output fluctuations in the United States: What has changed since the early 1980s?, Working Paper, Federal Reserve Bank of New York.

Mitchell, W.A., 1927, Business cycles: The problem and its setting (NBER, New York).

Neftci, S. N., 1984, Are economic time series asymmetric over the business cycle?, Journal of Political Economy 92, 307-328.

Nelson, C.R., J. Piger and E. Zivot, 1999, Unit root tests in the presence of Markov regime switching, Discussion Paper, Department of Economics, University of Washington. 
Perron, P., 1989, The great crash, the oil shock and the unit root hypothesis, Econometrica $57,1361-1401$.

Perron, P., 1994, Trend, unit root and structural change in macroeconomic time series, in B.B. Rao, ed, Cointegration for the applied economist (St. Martins Press, New York).

Sichel, D.E., 1993, Business cycle asymmetry: A deeper look, Economic Inquiry 31, 224236.

Sichel, D. E., 1994, Inventories and the three phases of the business cycle, Journal of Business and Economic Statistics 12, 269-277.

Startz, R., 1998, Growth states and shocks, Journal of Economic Growth 3, 203-215.

Wynne, M.A. and N.S. Balke, 1992, Are deep recessions followed by strong recoveries?, Economics Letters 39, 183-189.

Wynne, M.A. and N.S. Balke, 1996, Are deep recessions followed by strong recoveries? Results for the G-7 countries, Applied Economics 28, 889-897. 


\section{Table 1: Johansen $(1991,1995)$ Cointegration Tests \\ Quarterly data from 1952:1 - 1998:3}

\begin{tabular}{cccc} 
Null Hypothesis & Test Statistic $^{\mathbf{1 4}}$ & $\begin{array}{c}\mathbf{5 \%} \text { Critical } \\
\text { Value }\end{array}$ & $\begin{array}{c}\mathbf{1 \%} \text { Critical } \\
\text { Value }\end{array}$ \\
\hline \hline $\begin{array}{c}\text { No Cointegrating } \\
\text { Vectors }\end{array}$ & $36.51^{++}$ & 29.68 & 35.65 \\
$\begin{array}{c}\text { At Most One } \\
\text { Cointegrating Vector } \\
\text { At Most Two }\end{array}$ & $16.95^{+}$ & 15.41 & 20.04 \\
Cointegrating Vectors & 2.44 & 3.76 & 6.65
\end{tabular}

\footnotetext{
${ }^{14}$ The test statistic is the Likelihood Ratio statistic discussed in Johansen $(1991,1995)$ and calculated in Eviews using a levels lag order of 6. As in King, Plosser, Stock and Watson (1991), we assume that each series has a linear trend but the cointegrating equation has only intercepts.

${ }^{++}$Rejected at the $1 \%$ significance level.

${ }^{+}$Rejected at the $5 \%$ significance level.
} 
Table 2: Maximum Likelihood Estimates of Models 1 - 3

Quarterly data from 1952:1 - 1998:3

(Standard Errors in Parentheses)

\begin{tabular}{|c|c|c|c|c|c|c|c|c|c|}
\hline Parameter & Unres & tricted & & $\begin{array}{l}\text { Hami } \\
\text { Only }\end{array}$ & & & $\begin{array}{l}\text { "Pluc } \\
\text { Only }\end{array}$ & ring" & \\
\hline$\gamma_{y}, \gamma_{i}, \gamma_{c}$ & $\begin{array}{l}1^{*} \\
---\end{array}$ & $\begin{array}{l}1.08 \\
(0.04)\end{array}$ & $\begin{array}{c}0.93 \\
(0.01)\end{array}$ & $\begin{array}{l}1^{*} \\
---\end{array}$ & $\begin{array}{c}1.06 \\
(0.03)\end{array}$ & $\begin{array}{l}0.93 \\
(0.02)\end{array}$ & $\begin{array}{l}1^{*} \\
--\end{array}$ & $\begin{array}{l}1.04 \\
(0.03)\end{array}$ & $\begin{array}{c}0.95 \\
(0.01)\end{array}$ \\
\hline$\lambda_{y}, \lambda_{i}$ & $\begin{array}{l}1^{*} \\
---\end{array}$ & $\begin{array}{l}2.17 \\
(0.29)\end{array}$ & & $\begin{array}{l}1^{*} \\
---\end{array}$ & $\begin{array}{l}2.85 \\
(0.32)\end{array}$ & & $1^{*}$ & $\begin{array}{l}2.14 \\
(0.35)\end{array}$ & \\
\hline$\sigma_{v}, \sigma_{\omega}$ & $\begin{array}{c}0.43 \\
(0.03)\end{array}$ & $\begin{array}{c}0.73 \\
(0.08)\end{array}$ & & $\begin{array}{c}0.41 \\
(0.03)\end{array}$ & $\begin{array}{c}0.66 \\
(0.07)\end{array}$ & & $\begin{array}{c}0.49 \\
(0.03)\end{array}$ & $\begin{array}{c}0.71 \\
(0.07)\end{array}$ & \\
\hline$\sigma_{y}, \sigma_{i}$ & $\begin{array}{c}0.65 \\
(0.09)\end{array}$ & $\begin{array}{c}1.13 \\
(0.17)\end{array}$ & & $\begin{array}{c}0.78 \\
(0.06)\end{array}$ & $\begin{array}{c}0.75 \\
(0.34)\end{array}$ & & $\begin{array}{c}0.42 \\
(0.12)\end{array}$ & $\begin{array}{l}1.30 \\
(0.19)\end{array}$ & \\
\hline$\phi_{1}, \phi_{2}$ & $\begin{array}{c}1.34 \\
(0.07)\end{array}$ & $\begin{array}{l}-0.45 \\
(0.05)\end{array}$ & & $\begin{array}{c}1.44 \\
(0.06)\end{array}$ & $\begin{array}{l}-0.52 \\
(0.04)\end{array}$ & & $\begin{array}{c}1.32 \\
(0.08)\end{array}$ & $\begin{array}{l}-0.44 \\
(0.05)\end{array}$ & \\
\hline$\psi_{y 1}, \psi_{y 2}$ & $\begin{array}{c}0.57 \\
(0.16)\end{array}$ & $\begin{array}{c}0.12 \\
(0.10)\end{array}$ & & $\begin{array}{c}0.77 \\
(0.09)\end{array}$ & $\begin{array}{c}0.13 \\
(0.09)\end{array}$ & & $\begin{array}{c}0.43 \\
(0.05)\end{array}$ & $\begin{array}{c}0.43 \\
(0.07)\end{array}$ & \\
\hline$\psi_{i 1}, \psi_{i 2}$ & $\begin{array}{l}1.03 \\
(0.13)\end{array}$ & $\begin{array}{l}-0.10 \\
(0.12)\end{array}$ & & $\begin{array}{c}0.66 \\
(0.38)\end{array}$ & $\begin{array}{l}0.28 \\
(0.34)\end{array}$ & & $\begin{array}{l}1.19 \\
(0.09)\end{array}$ & $\begin{array}{l}-.26 \\
(0.09)\end{array}$ & \\
\hline$\mu_{0}, \mu_{0}^{k}$ & $\begin{array}{c}1.12 \\
(0.05)\end{array}$ & $\begin{array}{c}0.87 \\
(0.08)\end{array}$ & & $\begin{array}{l}1.12 \\
(0.07)\end{array}$ & $\begin{array}{c}0.85 \\
(0.07)\end{array}$ & & $\begin{array}{l}1.02 \\
(0.06)\end{array}$ & $\begin{array}{c}0.72 \\
(0.05)\end{array}$ & \\
\hline$\mu_{1}$ & $\begin{array}{l}-0.68 \\
(0.11)\end{array}$ & & & $\begin{array}{l}-0.77 \\
(0.17)\end{array}$ & & & --- & & \\
\hline$\tau_{y}, \tau_{i}$ & $\begin{array}{l}-0.93 \\
(0.44)\end{array}$ & $\begin{array}{l}-2.01 \\
(0.76)\end{array}$ & & -- & --- & & $\begin{array}{l}-2.92 \\
(0.39)\end{array}$ & $\begin{array}{l}-3.20 \\
(0.65)\end{array}$ & \\
\hline$p_{00}, p_{11}$ & $\begin{array}{c}0.95 \\
(0.02)\end{array}$ & $\begin{array}{c}0.79 \\
(0.09)\end{array}$ & & $\begin{array}{c}0.95 \\
(0.02)\end{array}$ & $\begin{array}{c}0.73 \\
(0.14)\end{array}$ & & $\begin{array}{c}0.96 \\
(0.02)\end{array}$ & $\begin{array}{c}0.43 \\
(0.15)\end{array}$ & \\
\hline$q_{00}$ & $\begin{array}{c}0.99 \\
(0.01) \\
\end{array}$ & & & $\begin{array}{c}0.99 \\
(0.01) \\
\end{array}$ & & & $\begin{array}{c}0.99 \\
(0.01) \\
\end{array}$ & & \\
\hline Log Likelihood & -227.33 & & & -234.72 & & & -231.48 & & \\
\hline
\end{tabular}

\footnotetext{
* Normalized to unity for identification.
} 
Table 3: Parameter Estimates for Hamilton's (1989) Model Applied to Data Generated with 'Plucking”' Recessions

\begin{tabular}{ccc} 
Parameter & Estimate & $\begin{array}{l}\text { Standard } \\
\text { Error }\end{array}$ \\
\hline \hline$\tilde{\mu}_{0}$ & 1.11 & 0.09 \\
$\tilde{\mu}_{1}$ & -0.19 & 0.42 \\
$\tilde{p}_{11}$ & 0.79 & 0.15 \\
$\tilde{p}_{00}$ & 0.98 & 0.02 \\
$\theta_{1}$ & 0.25 & 0.08 \\
$\theta_{2}$ & -0.04 & 0.08 \\
$\sigma_{\mathrm{K}}^{2}$ & 0.82 & 0.05 \\
\hline \hline
\end{tabular}


Figure 1:

A Recession With Only Hamilton Type Asymmetry

(Solid lines indicate trend, dashed lines indicate deviations from trend)

Level of Output

Time 
Figure 2:

A Recession With Only "Plucking" Type Asymmetry

(Solid lines indicate trend, dashed lines indicate deviations from trend)

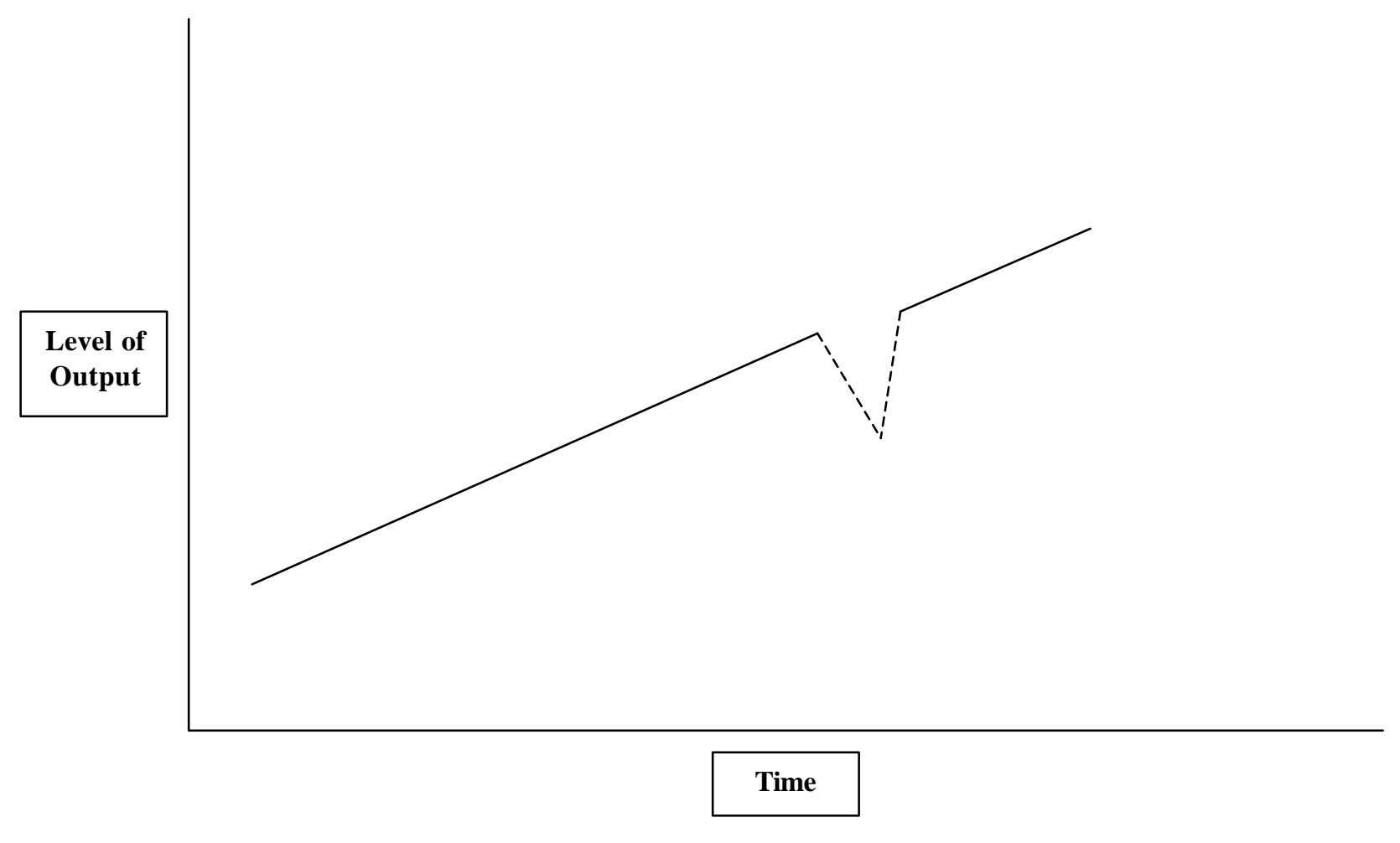


Figure 3: Log Consumption of Non-Durables and Services (Shaded Areas Indicate NBER Recession Dates)

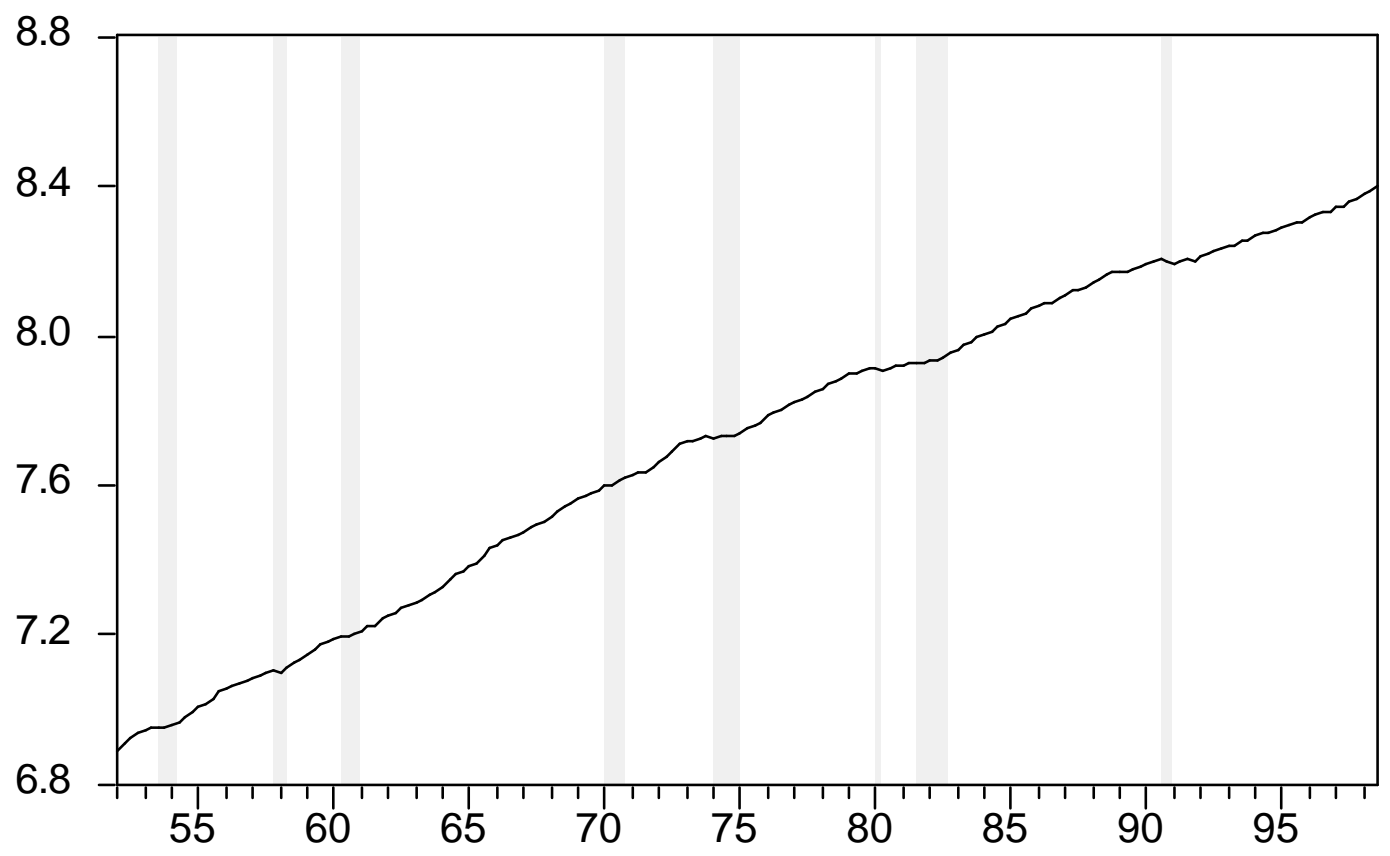

Figure 4: Equilibrium Errors for Log Output and Log Investment (Shaded Areas Indicate NBER Recession Dates)

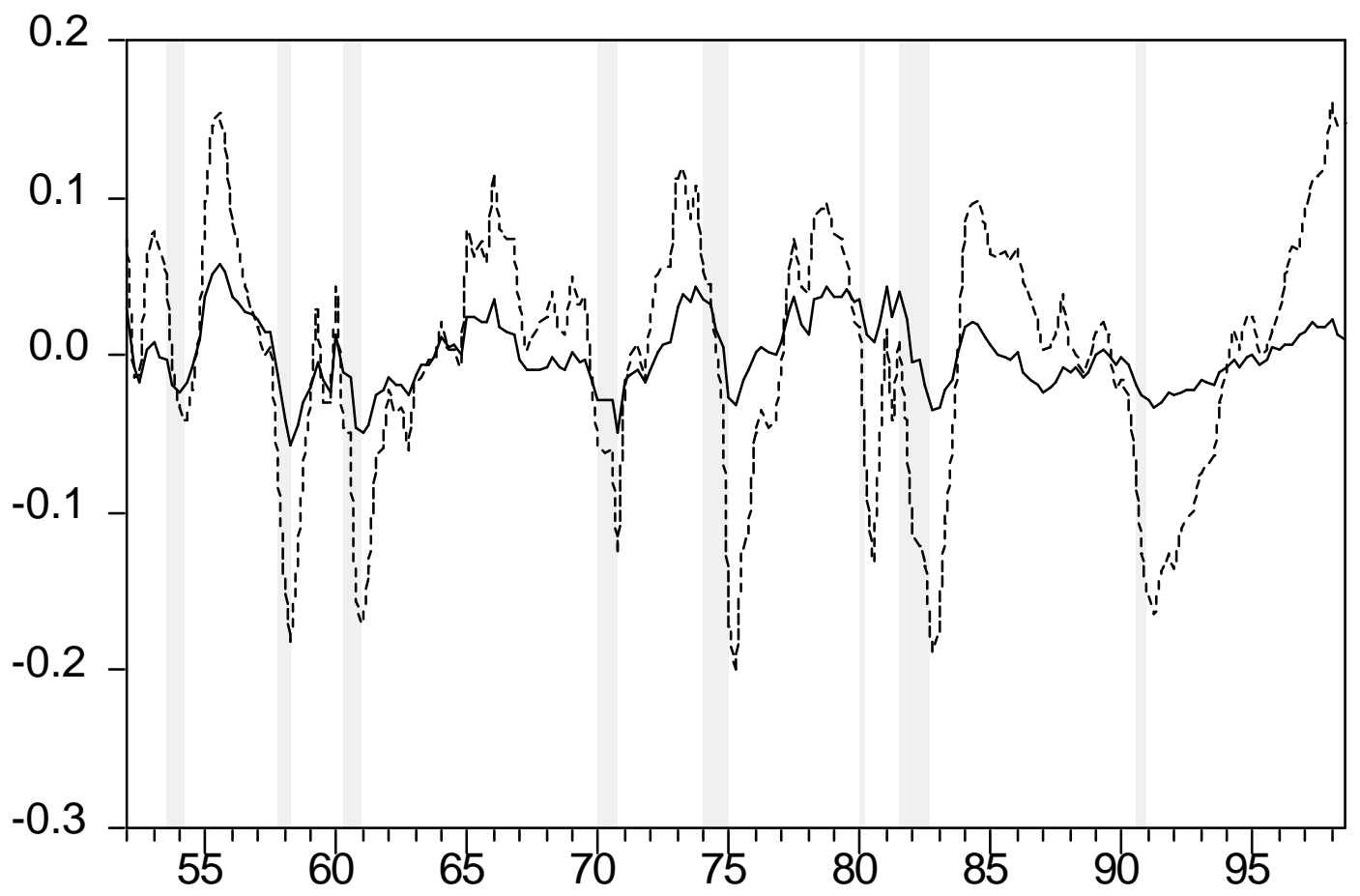


Figure 5: Filtered Probability that $S_{t}=1$

(Shaded Areas Indicate NBER Recession Dates)

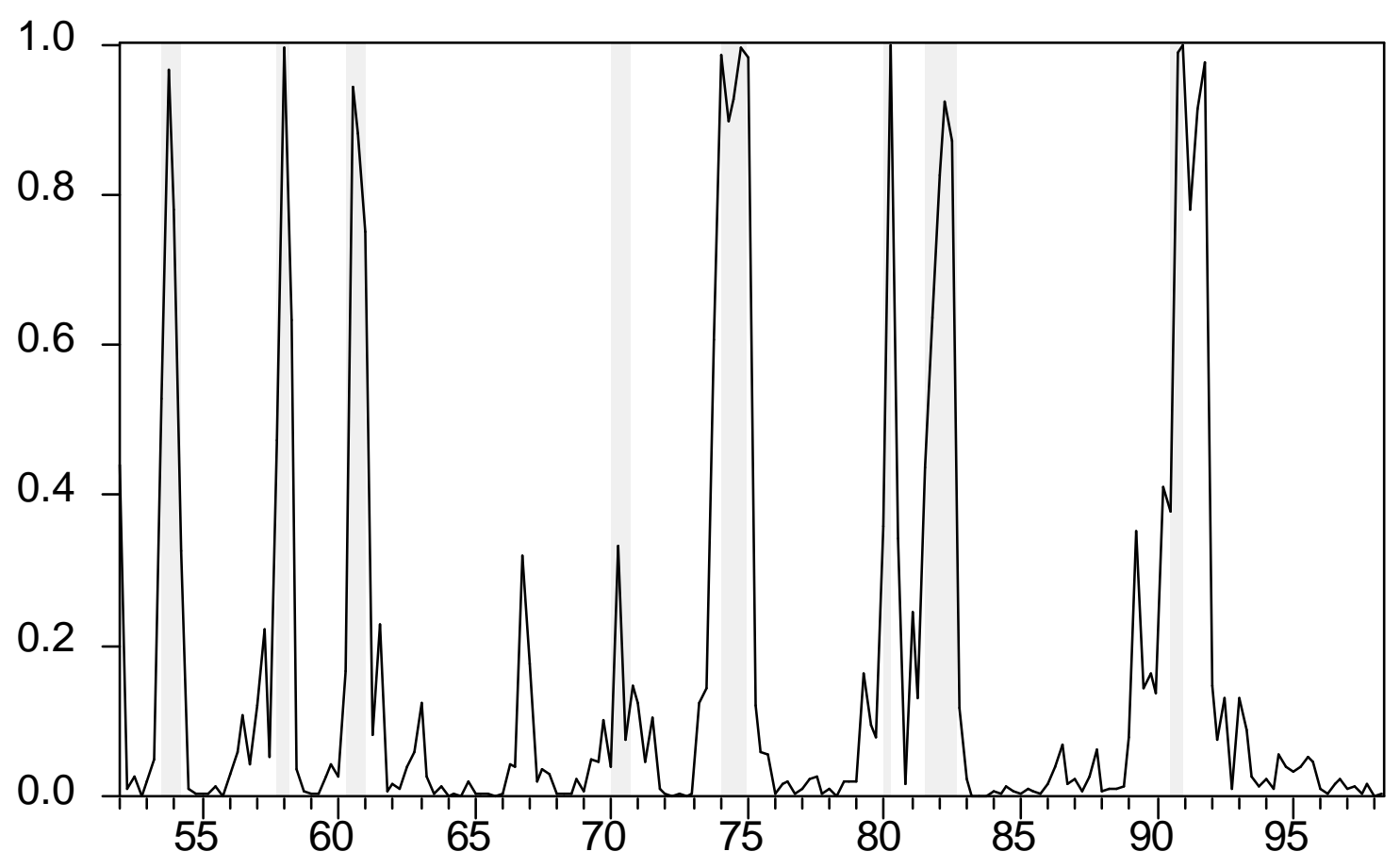

Figure 6: Smoothed Probability that $S_{t}=1$

(Shaded Areas Indicate NBER Recession Dates)

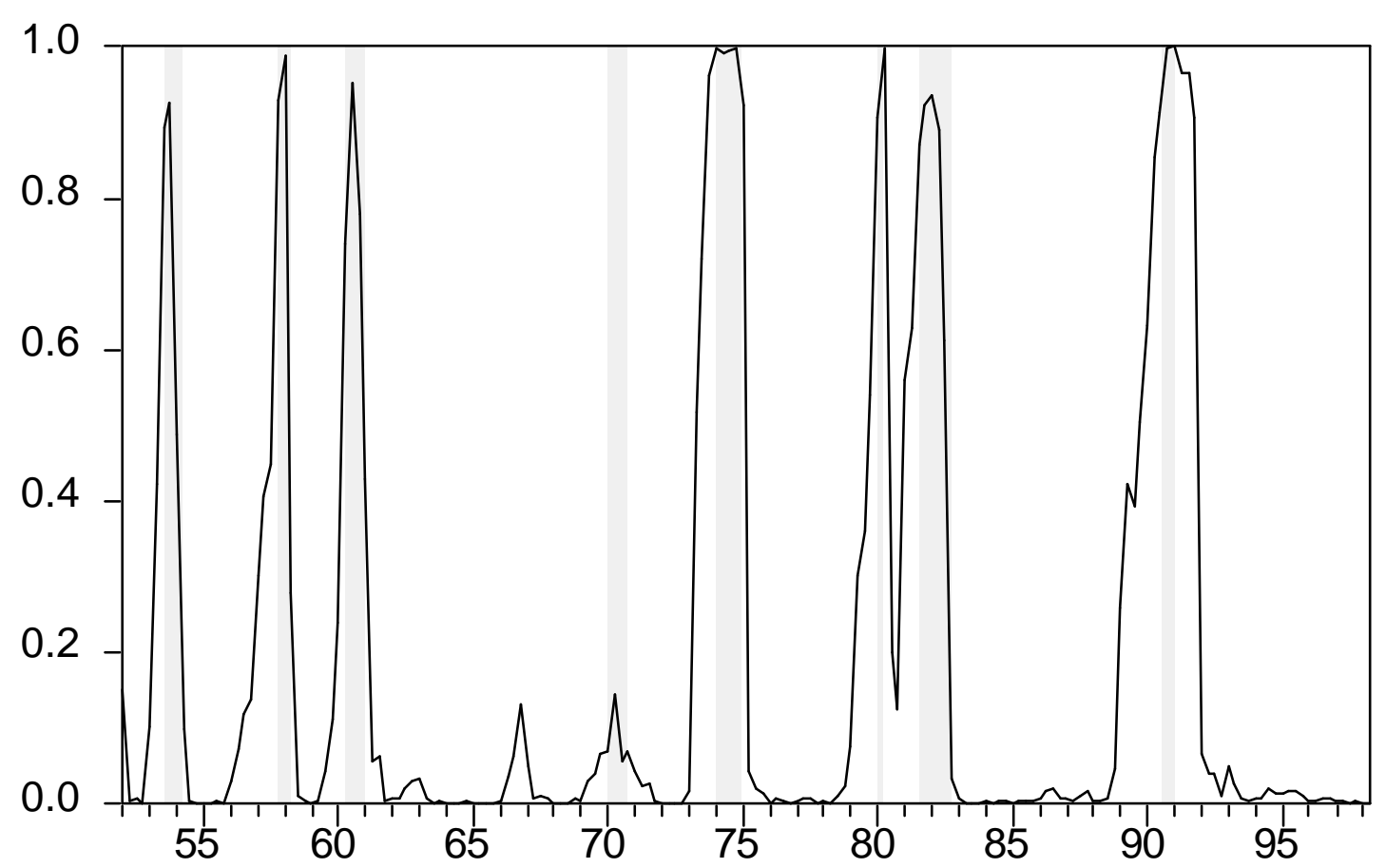


Figure 7: Smoothed Probability that $D_{t}=1$

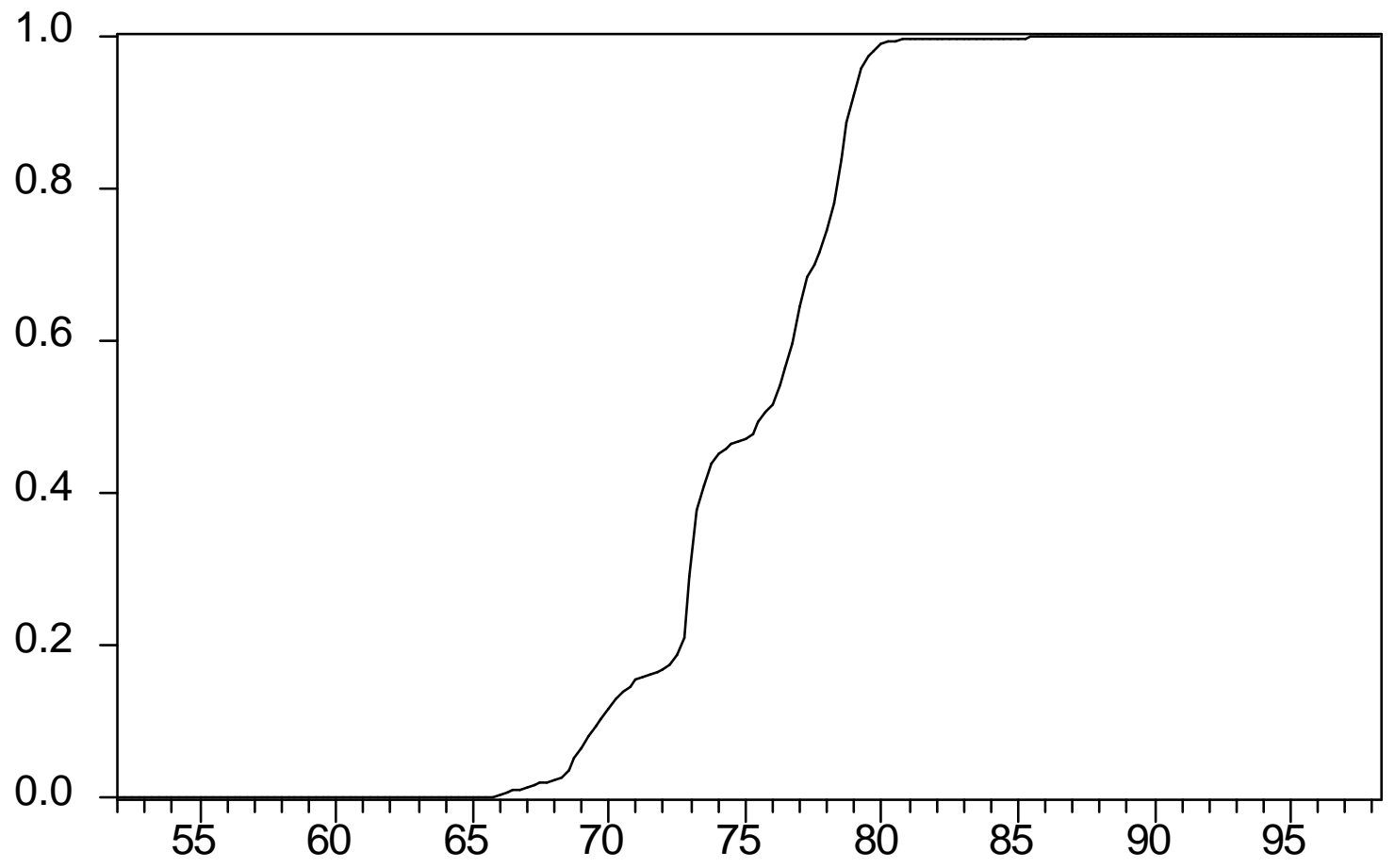


Figure 8: A Recession with Both Hamilton and "Plucking" Types of Asymmetry (Solid lines indicate trend, dashed lines indicate deviations from trend)

Level of Output

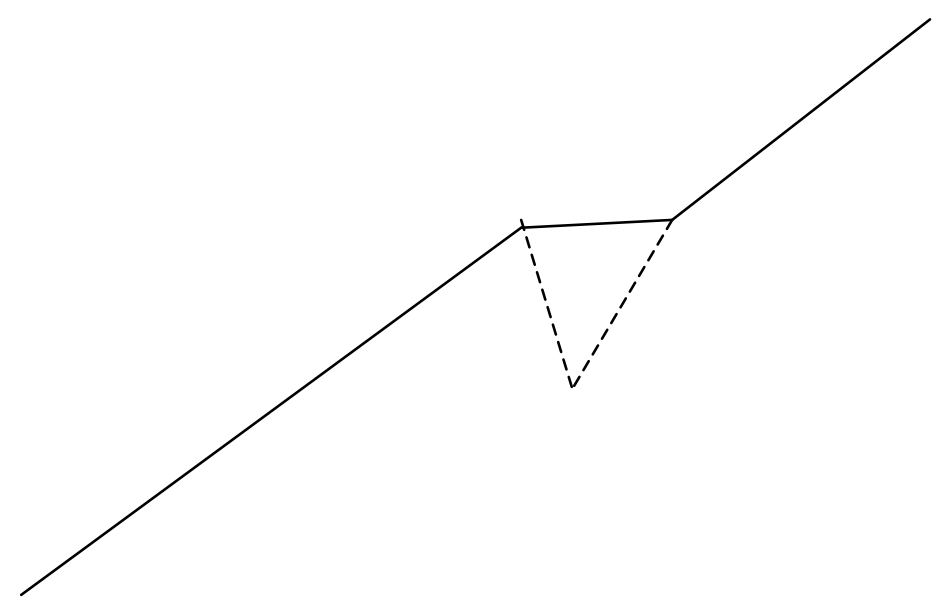

Time 